Journal of Computer Science 7 (7): 1105-1112, 2011

ISSN 1549-3636

(C) 2011 Science Publications

\title{
Performance of MMSE Receiver based Multi Input Multi Output-Interleave Division Multiple-Access System with Multi-user Detection over Frequency Selective Wireless Communication Channel
}

\author{
${ }^{1}$ Kuttathatti Srinivasan Vishvaksenan and ${ }^{2}$ R. Seshasayanan \\ ${ }^{1}$ Department of Electronics and Communication Engineering, \\ SSN College of Engineering, Chennai, India \\ ${ }^{2}$ Department of Electronics and Communication Engineering, \\ College of Engineering, Guindy Anna University, Chennai, India
}

\begin{abstract}
Problem statement: This study presents the performance analysis of turbo assisted Interleave Division Multiple-Access (IDMA) system with Multi Input Multi Output (MIMO) support for multi user scenario over correlated frequency selective and uncorrelated frequency selective channel. Approach: The key principle of IDMA is that interleaver unique which distinguishes the users in contrast to spreading sequence in Code Division Multiple Access System (CDMA). Results: In this work, we assume that Interleavers are generated independently and randomly. At the receiver, we employed Ordered SIC (OSIC) technique using ZF and MMSE criterion to combat Inter Antenna Interference (IAI) and Multi User Interference (MUI) problem along with iterative decoding to improve the performance in terms of BER. The performance of system has been discussed for different channel conditions with realistic channel model using extensive simulation runs based on Monte Carlo simulation trials. We have exhibited the flexibility and robustness provided by MIMO-IDMA. Conclusion/Recommendations: It has been proved from the results that IDMA principle can be applied to realize many potential performance gains highlighted by information theory, including coding gain multiplexing gain and multiuser gain. Simulation results presented to demonstrate the benefits of IDMA with MUD and iterative decoding. It is discerned that IDMA performs better than CDMA in frequency selective channel for high load conditions which is assessed through computer simulation results.
\end{abstract}

Key words: Multi-User Interference (MUI), Multiple Antenna Interference (MAI), Code Division Multiple Access (CDMA), Stanford University Interim (SUI), channel capacity, iterative decoding, Log-Likelihood Ratio (LLR), Multi Input Multi Output (MIMO)

\section{INTRODUCTION}

Code division multiple access system is the most widely used system for multi-user communications. But the performance of CDMA (Sreedhar and Chockalingam, 2006) is limited by multiple access interference and inter symbol interference. With CDMA fading is circumvented by the use of interleavers placed between FEC and spreading. After the invention of joint Turbo type receivers, extensive studies have been made to mitigate MAI and ISI (Schoeneich and Hoeher, 2004; Telatar, 1999; Nagaradjane et al., 2009a; 2009b) employing joint detection and decoding. But high complexity of optimal detection precludes its implementation for signal detection. Recently asynchronous multiple access scheme called interleave Division Multiple-Access (IDMA) (Novak et al., 2007) system have been widely studied the use of random sequences (i.e., random coding) for Communication forms the core of information theory. The framework of InterleaveDivision Multiple-Access (IDMA) is closely related to random coding. In an IDMA scheme, different interleavers are used to distinguish users as against different codes in a conventional Code Division Multiple Access (CDMA) system. These interleavers are selected randomly and orthogonality propertry need not be essential. In a conventional CDMA scheme, interleavers are placed before the spreaders and they are effective only when used in conjunction with channel coding (Ping et al., 2003; Schoeneich and Hoeher, 2004). Recently, a very interesting technique using chip-level interleavers was addressed in (Novak et al., 2007), which aims at mitigating Intersymbol Interference (ISI) in multipath fading environments. Many works have discussed the role of interleavers in

Corresponding Author: Kuttathatti Srinivasan Vishvaksenan, Department of Electronics and Communication Engineering, SSN College of Engineering, Chennai, India 


\section{J. Computer Sci., 7 (7): 1105-1112, 2011}

multiple access systems (Novak et al., 2007; Schoeneich and Hoeher, 2004). IDMA inherits many benefits of CDMA; in particular, path diversity and mitigation of intra cell interference. Also all the users employ a common spreading sequence.

\section{MATERIALS AND METHODS}

The Shannon's capacity theorem states that $\mathrm{C}=\mathrm{W} \log _{2}(1+\mathrm{SNR}) \mathrm{bits} / \mathrm{sec}$ Where $C$-capacity, WBandwidth, SNR-signal to noise ratio. For fixed bandwidth, capacity can be increased by means of multiple antennas both at the transmitter and receiver:

$\mathrm{C}=\mathrm{MW} \log _{2}(1+\mathrm{SNR})$ bits $/ \mathrm{sec}$

where, $\mathrm{M}=\min \left(\mathrm{N}_{\mathrm{t}}, \mathrm{Nr}\right)$ where $\mathrm{N}_{\mathrm{t}}$-transmitter antenna and $\mathrm{N}_{\mathrm{r}}$-receiver antenna. Hence Use of MIMO (Multiple-Input Multiple-Output) (Novak et al., 2007; Sayadi et al., 2009; Muthaiyah, 2004) systems which employ multiple antennas at the transmitter and receiver to multi-user environments can provide higher throughput and error performance (less error probability) without any additional expenditure in bandwidth or transmitted power. MIMO system with appropriate processing can provide spatial multiplexing to achieve high data rate communications or diversity to overcome multipath effects. So combining MIMO with the IDMA system can result in MIMO-IDMA that can offer bandwidth efficiency (Prabagarane et al., 2008), space multiplexing and lower speed parallel type of signal processing and interference rejection capability (ISI reduction) in high data-rate transmission.

Multi-user Detection (MUD) (Prabagarane et al., 2008; Verdu, 1998) is based on the idea of detecting interference and exploiting the resulting knowledge to mitigate its effect on the desired signal. Prabagarane et al. (2008) several low cost detection algorithm for IDMA scheme have been addressed. Also a semi analytical treatment to estimate the BER performance of several less complex detection algorithm based on SNR evolution is addressed in (Telatar, 1999). Non iterative MUD for dealing with MAI problem have been widely addressed. Brink (2001) iterative MUD based on turbo principle and its potential merits is considered.

In this study, we investigate the performance of the MIMO assisted Interleave Division Multiple Access (MIMO-IDMA) scheme with multi-user detection and iterative decoding over both correlated and uncorrelated frequency selective fading channel aided by sub-optimal detector such as zero forcing and MMSE algorithm for three types of delay spread based on SUI channel model (Table 1).

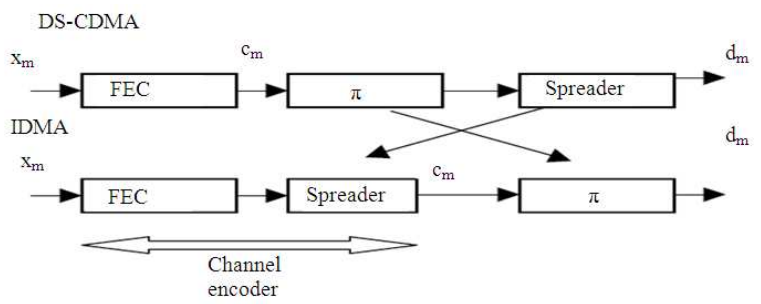

Fig. 1: Comparison of conventional DS-CDMA with IDMA

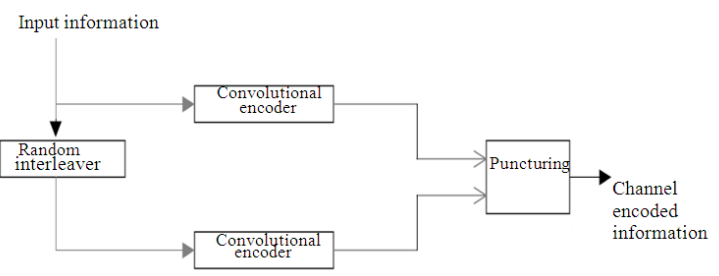

Fig. 2: Structure of turbo encoder

The rest of the study is organized as follows-. System model is presented in section II. Section III gives the essence of signal detection techniques. Section IV illustrates chip-by-chip detection. Performance results are presented in section $\mathrm{V}$ to validate analytical results and section VI concludes our study.

System model: The data sequence of the m-th layer is denoted as $\mathrm{x}_{\mathrm{m}}$ and the corresponding encoded and interleaved sequence is denoted as $\mathrm{d}_{\mathrm{m}}$.

A DS-CDMA system is illustrated where interleaver is closely attached to the FEC encoder and the use of signature sequences for user separation is a characteristic feature for a conventional CDMA system (Brink, 2001). Interleaving, which is usually placed between Forward Error Correction (FEC) coding and spreading, is employed to combat fading effect. The arrangement of interleaving $(\pi)$ and spreading $(\mathrm{C})$ is reversed in IDMA and a single low-rate encoder, subsequently denoted bychannel encoder may do FEC encoding and spreading jointly Fig. 1. Now, different interleavers distinguish distinct data streams. Furthermore, it is important to note that interleaving is done on a chip-by-chip basis. This special case of DSCDMA is called code-spread CDMA, chip-interleaved CDMA (cI-CDMA), or interleave-division multiple access (IDMA) inthe turbo codes are typically generated with parallel-concatenated convolutional encoder with large interleavers which is indicated in the Fig. 2. 
Table 1: Channel model parameters for SUI and rayleigh channel

\begin{tabular}{|c|c|c|c|c|c|c|c|c|}
\hline \multirow[b]{2}{*}{$\begin{array}{l}\text { Path number } \\
\text { (l) }\end{array}$} & \multicolumn{2}{|l|}{ SUI-1 } & \multicolumn{2}{|l|}{ SUI-3 } & \multicolumn{2}{|l|}{ SUI-5 } & \multicolumn{2}{|c|}{$\begin{array}{l}\text { Rayleighfading } \\
\text { channel }\end{array}$} \\
\hline & $\begin{array}{l}\text { Delay } \\
(\mathrm{ms})\end{array}$ & $\begin{array}{l}\text { Power } \\
(\mathrm{dB}) \\
\Psi(\tau)\end{array}$ & $\begin{array}{l}\text { Delay } \\
(\mathrm{ms})\end{array}$ & $\begin{array}{l}\text { Power } \\
\text { (dB) } \\
\Psi(\tau)\end{array}$ & $\begin{array}{l}\text { Delay } \\
(\mathrm{ms})\end{array}$ & $\begin{array}{l}\text { Power } \\
\text { (dB) } \\
\Psi(\tau)\end{array}$ & $\begin{array}{l}\text { Delay } \\
(\mathrm{ms})\end{array}$ & $\begin{array}{l}\text { Power } \\
(\mathrm{dB}) \\
\Psi(\tau)\end{array}$ \\
\hline 1 & 0 & 0 & 0 & 0 & 0 & 0 & 0.1 & 2 \\
\hline 2 & 0.4 & -15 & 0.4 & -5 & 4 & -5 & 0.2 & 3 \\
\hline 3 & 0.9 & -20 & 0.9 & -10 & 10 & -10 & 0.3 & 4 \\
\hline
\end{tabular}

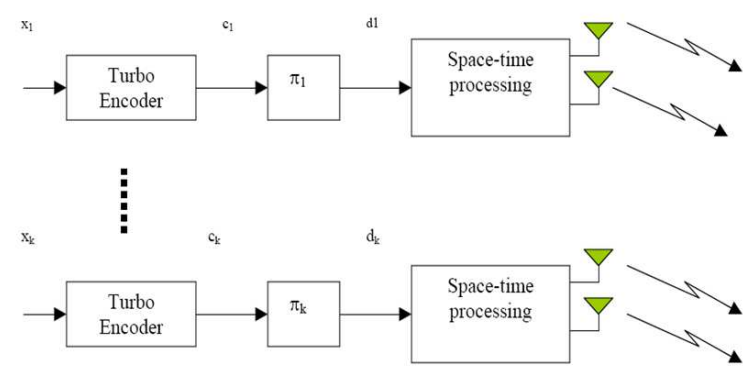

(a)

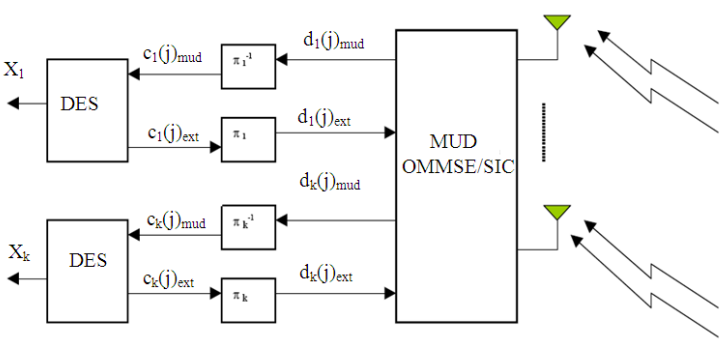

(b)

Fig. 3: System overview of (a) transmitter and (b) (iterative) receiver structures of an MIMO-IDMA scheme for Up Link communication

Figure 3 shows the block diagram of IDMA system. In this contribution, we consider K-user up-link communication with each mobile station equipped with 2 transmitter antenna and the base station equipped with 2 receiver antenna .Let $\mathrm{Nt} X 2$ component transmitted vector of $\mathrm{k}^{\text {th }}$ user be denoted by $\mathrm{d}_{\mathrm{k}}=\left[\mathrm{d}_{1}(1), \ldots \mathrm{d}_{\mathrm{Nt}}\right]^{\mathrm{T}}$.

This dk will be transmitted to $\mathrm{M}$ base station.

In this contribution, we assume that channel matrix that connects $\mathrm{K}_{\mathrm{th}}$ user and $\mathrm{M}_{\mathrm{th}}$ base station is frequency selective. The channel model (Sayadi et al., 2009) assumed in our work is based on SUI with rich spatial scattering. The channel profile are detailed in Table 1 .

With the help of the parameter defined in Table 1, the impulse response from ith transmitter antenna to jth receiver antenna may be defined as:

$$
h_{j i}(t)=\sum_{\mathrm{l}=1}^{\mathrm{L}} \mathrm{h}_{\mathrm{ji}}^{1} \partial\left(t-\tau_{1}\right)
$$

where, $\mathrm{h}_{\mathrm{ji}}^{1}$ is a complex zero-mean Gaussian random process with variance $\Psi\left(\tau_{1}\right)$. Also, $h_{\mathrm{ji}}^{1}$ is correlated with other paths and channels. L denotes the total number of paths between the $\mathrm{i}_{\text {th }}$ transmit and the $\mathrm{j}_{\text {th }}$ receive antenna.

The $\mathrm{N}_{\mathrm{r}}$ length Up Link received vector $\mathrm{y}$ at the $\mathrm{m}_{\mathrm{th}}$ base station can be expressed as:

$$
\begin{aligned}
& \mathrm{y}=\sum_{\mathrm{k}=1}^{\mathrm{K}} \mathrm{H}_{\mathrm{k}} \mathrm{d}_{\mathrm{k}}+\mathrm{n} \\
& =\underbrace{\mathrm{H}_{\mathrm{k}} \mathrm{d}_{\mathrm{k}}}_{\substack{\text { Desired } \\
\text { SIgnal }}}+\underbrace{\sum_{\mathrm{i}=1, \mathrm{i} \neq \mathrm{k}}^{\mathrm{K}} \mathrm{H}_{\mathrm{k}} \mathrm{d}_{\mathrm{i}}}_{\text {MAI }}+\mathrm{n} \\
& \mathrm{k}=1,2, \ldots, \mathrm{K}
\end{aligned}
$$

\section{Signal detection technique:}

AV-BLAST-Zero forcing/OSIC detector: For user-k, the corresponding ESE outputs $\left\{\mathrm{L}\left(\mathrm{d}_{\mathrm{k}}(\mathrm{j})\right), \mathrm{j}=1,2, \ldots \mathrm{J}\right\}$ are de-interleaved to form $\left\{\mathrm{L}\left(\mathrm{d}_{\mathrm{k}}(\mathrm{j})\right), \mathrm{j}=1,2, \ldots \mathrm{J}\right\}$ and delivered to the DES for user-k. The DES performs a soft-in/soft-out chip-by-chip de-spreading operation as detailed below. For simplicity, we focus on the chips related to $\mathrm{d} 1(\mathrm{k})$, the first bit of user-k. The treatment for other chips is similar.

The V-BLAST detection algorithm (Nagaradjane et al., 2009a) is a recursive procedure that extracts the components of the transmitted vector $\mathrm{d}$ according to a certain ordering $\left(\mathrm{k}_{1}, \mathrm{k}_{2} \ldots \mathrm{k}_{\mathrm{M}}\right)$ of the elements of $\mathrm{d}$, where, $\left(\mathrm{k}_{1}, \mathrm{k}_{2} \ldots \mathrm{k}_{\mathrm{M}}\right)$ is a permutation of $(1 \ldots \mathrm{M})$. In VBLAST, this permutation depends on $\mathrm{H}$ (which is known at the receiver by assumption) but not on the received vector $r$. in this study, we have considered suboptimal detector such as ZF and MMSE to realize the performance. The VBLAST/ZF algorithm is a variant of VBLAST derived from ZF rule. The algorithm determines the order of layers to be detected performs nulling and computes the decision statistics. It then slices the computed decision statistics and yields the decision by performing cancellation with the help of decision feedback and finally computes the new pseudo-inverse for the next iteration. V-BLAST/ZF 


\section{J. Computer Sci., 7 (7): 1105-1112, 2011}

may be seen as a successive-cancellation scheme derived from the $\mathrm{ZF}$ scheme:

$\mathrm{W}_{1}=\mathrm{H}^{+}$

where, $\mathrm{W}$ is the weight matrix that depends on the channel fading $\mathrm{H}$.

$\mathrm{i}=1$

Recursion:

$\mathrm{k}_{\mathrm{i}}=\underset{\mathrm{j} \notin\left\{\mathrm{k}_{1} \ldots . \mathrm{k}_{\mathrm{i}-1}\right\}}{\arg \max }\left\|\left(\mathrm{W}_{\mathrm{i}}\right)_{\mathrm{j}}\right\|$

$\mathrm{Y}_{\mathrm{k}_{\mathrm{i}}}=\left(\mathrm{W}_{\mathrm{i}}\right)_{\mathrm{k}_{\mathrm{i}}} \mathrm{r}_{\mathrm{i}}$

$\hat{\mathrm{a}}_{\mathrm{k}_{\mathrm{i}}}=\mathrm{Q}\left(\mathrm{Y}_{\mathrm{k}_{\mathrm{i}}}\right)$

$\mathrm{r}_{\mathrm{i}+1}=\mathrm{r}_{\mathrm{i}}-\hat{\mathrm{a}}_{\mathrm{k}_{\mathrm{i}}}(\mathrm{H})_{\mathrm{k}_{\mathrm{i}}}$

$\mathrm{W}_{\mathrm{i}+1}=\mathrm{H}_{\overline{\mathrm{k}}_{\mathrm{i}}}^{+}$

where, $\mathrm{H}^{+}$is the Moore-Penrose pseudo-inverse of $\mathrm{H}$, the channel matrix. $\left(\mathrm{W}_{\mathrm{i}}\right)_{\mathrm{j}}$ is the $\mathrm{j}^{\mathrm{th}}$ row of $\mathrm{W}_{\mathrm{i}} \mathrm{Q}($.$) is a$ quantizer to the nearest signal point, $(\mathrm{H})_{\mathrm{k}_{\mathrm{i}}}$ denotes the $\mathrm{k}_{\mathrm{i}}$ th column of $\mathrm{H} . \mathrm{H} \pm_{\mathrm{k}_{\mathrm{i}}}$ denotes the matrix obtained by zeroing the columns $\mathrm{k}_{1} \mathrm{k}_{2} \ldots \ldots \ldots \mathrm{k}_{\mathrm{i}}$ of $\mathrm{H}$.. In the above algorithm, zf-1 determines the order of the channels to be detected. This is done by choosing the channels with the smallest noise variance. Using Eq. 4 the corresponding layer is decided based on the smallest noise variance and quantization is performed with the help of the Eq. 6. In Eq. 7 interference mitigation is performed through decision feedback. Equation 8 calculates the weight matrix for the next iteration. The $\mathrm{ZF}$ creates set of sub-channels by forming:

$\hat{\mathrm{a}}_{\mathrm{zf}}=\left(\mathrm{H}^{+} \mathrm{H}\right) \mathrm{a}+\mathrm{H}^{+} \mathrm{v}$

The order selection rule prioritizes the sub-channel with the smallest noise variance.

V-BLAST-MMSE/OSIC detector: The VBLAST/MMSE algorithm is a variant of $\mathrm{V}$-BLAST/ZF where the Weight matrix is chosen based on the MMSE rule:

$\mathrm{W}_{1}=\left(\mathrm{H}^{\mathrm{H}} \mathrm{H}+\sigma^{2} \mathrm{I}_{\mathrm{nT}}\right)^{-1} \mathrm{H}^{\mathrm{H}}$ $\mathrm{i}=1$

Recursion:

$\mathrm{k}_{\mathrm{i}}=\underset{\mathrm{j} \notin\left\{\mathrm{k}_{1} \ldots \mathrm{k}_{\mathrm{i}-1}\right\}}{\arg \max }\left\|\left(\mathrm{W}_{\mathrm{i}}\right)_{\mathrm{j}}\right\|$

$\mathrm{Y}_{\mathrm{k}_{\mathrm{i}}}=\left(\mathrm{W}_{\mathrm{i}}\right)_{\mathrm{k}_{\mathrm{i}}} \mathrm{r}_{\mathrm{i}}, \hat{\mathrm{a}}_{\mathrm{k}_{\mathrm{i}}}=\mathrm{Q}\left(\mathrm{Y}_{\mathrm{k}_{\mathrm{i}}}\right)$

$\mathrm{r}_{\mathrm{i}+1}=\mathrm{r}_{\mathrm{i}}-\hat{\mathrm{a}}_{\mathrm{k}_{\mathrm{i}}}(\mathrm{H})_{\mathrm{k}_{\mathrm{i}}}$

$\mathrm{W}_{\mathrm{i}+1}=\mathrm{H}_{\mathrm{k}_{\mathrm{i}}}^{+}$

$\mathrm{i}=\mathrm{i}+1$

$\mathrm{W}_{\mathrm{i}+1}=\left(\mathrm{H}_{\overline{\mathrm{k}} \mathrm{i}}{ }^{\mathrm{H}} \mathrm{H}_{\overline{\mathrm{k}} \mathrm{i}}+\sigma^{2} \mathrm{I}_{\mathrm{nT}}\right)^{-1} \mathrm{H}_{\overline{\mathrm{k}} \mathrm{i}}{ }^{\mathrm{H}}$

The MMSE Interference cancellation receiver suppresses both interference and noise component (Sreedhar and Chockalingam, 2006; Almutairi et al., 2003), which means that the mean square error or variance between the transmitted symbols and the estimate is reduced.

Chip by chip detection: The a posteriori LLR for $x_{k}(j)$ can be computed using $\left\{\mathrm{L}_{\mathrm{k}}(\mathrm{c}(\mathrm{j}))\right\}$ as:

$$
\begin{aligned}
L\left(x_{k}(j)\right) & \equiv \log \left[\frac{\operatorname{Pr}\left(x_{k}(j)=+1 \mid r\right)}{\operatorname{Pr}\left(x_{k}(j)=-1 \mid r\right)}\right] \\
& =\sum_{j=1}^{S} s_{k}(j) L\left(c_{k}(j)\right)
\end{aligned}
$$

The extrinsic LLR for a chip cj(k) within $\mathrm{d} 1(\mathrm{k}) \mathrm{s}(\mathrm{k})$ is defined by:

$\left(c_{k}(j)\right)_{\text {Ext }} \equiv \log \left[\frac{\operatorname{Pr}\left(c_{k}(j)=+1 \mid r\right)}{\operatorname{Pr}\left(c_{k}(j)=-1 \mid r\right)}\right]-L\left(c_{k}(j)\right)$

The extrinsic LLRs $\left\{\left(c_{k}(j)_{\text {Ext }}\right)\right\}$ form the outputs of the DES and are fed back to the ESE after interleaving. In the next iteration, $\left\{\operatorname{Ext}\left(\mathrm{d}_{\mathrm{k}}(\mathrm{j})\right)\right\}$ are used to update $\left\{\mathrm{E}\left(\mathrm{d}_{\mathrm{k}}(\mathrm{j})\right)\right\}$ and $\left.\left\{\operatorname{var} \mathrm{d}_{\mathrm{k}}(\mathrm{j})\right)\right\}$ as:

$E\left(d_{k}(j)\right)=\frac{\exp \left(\left(d_{k}(j)\right)_{E x t}\right)-1}{\exp \left(\operatorname{Ext}\left(d_{k}(j)\right)\right)+1}=\tanh \left[\frac{\left(d_{k}(j)\right)_{E x t}}{2}\right]$ 


\section{J. Computer Sci., 7 (7): 1105-1112, 2011}

The iterations are carried out until mean $=1$ and variance $=0$.

\section{RESULTS AND DISCUSSION}

In this section, we present the simulation results of our analysis. Table 2 summarizes the simulation parameters.

Table 2: Simulation parameter

\begin{tabular}{ll}
\hline Parameter & Attributes \\
\hline Modulation technique & BPSK \\
Channel spacing & $20 \mathrm{MHz}$ \\
Sampling frequency & $22.5 \mathrm{MHz}$ \\
Number of transmitter antenna & 2 \\
Number of Receiver antenna & 2 \\
Channel Model & SUI-1, SUI-2, SUI-3 \\
& channel model, \\
& Frequency selective \\
Channel coding & fading channel \\
\end{tabular}

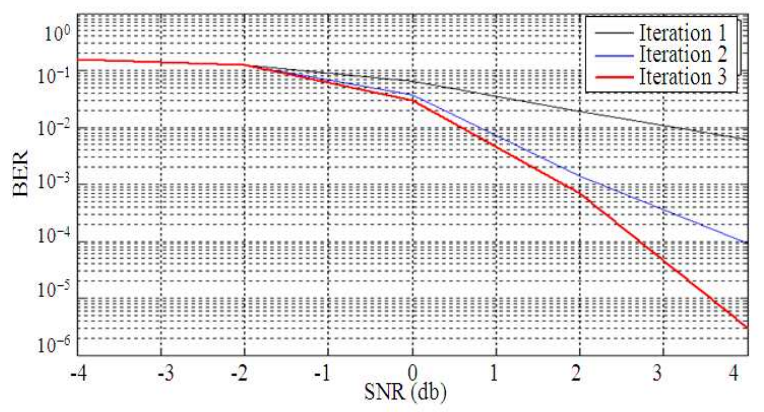

Fig. 4: Bit Error Rates (BER) performance of coded IDMA-MIMO MMSE with 50 users for Rayleigh fading channel

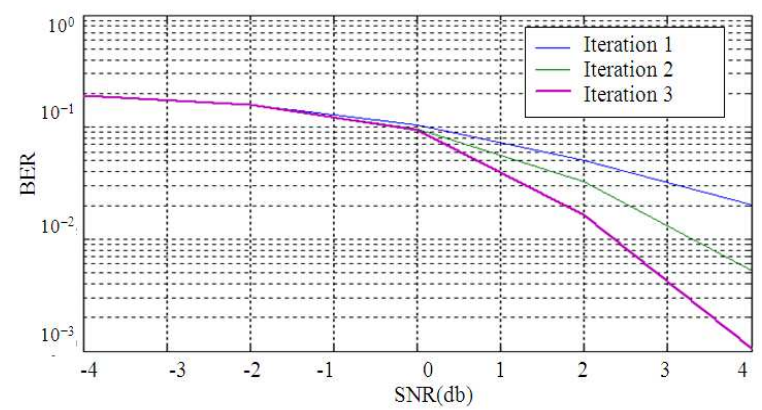

Fig. 5: Bit Error Rates (BER) performance of coded IDMA-MIMO MMSE with 50 users over correlated Rayleigh fading channel
The Fig. 4 expounds MIMO-IDMA System with MMSE Detector for 50 users employing MUD with 3 iteration. The Fig. 5 indicates MIMO-IDMA System with MMSE Detector for 50 users employing MUD with 3 iteration over correlated channel. The Fig. 6 and 7 shows the comparison of ZF and MMSE detector for rayleigh fading channel over correlated and uncorrelated channel. The Fig. 8 evince the effect of correlation on the MIMO channel for MMSE Detector. The Fig. 9 evince comparison results for an MIMOIDMA System and MIMO-CDMA system with MMSE detector for Rayleigh fading channel. The Fig. 10-12 elucidate the results for an MIMO-IDMA system with ZF detector for SUI 1, 3, 5 channel model.

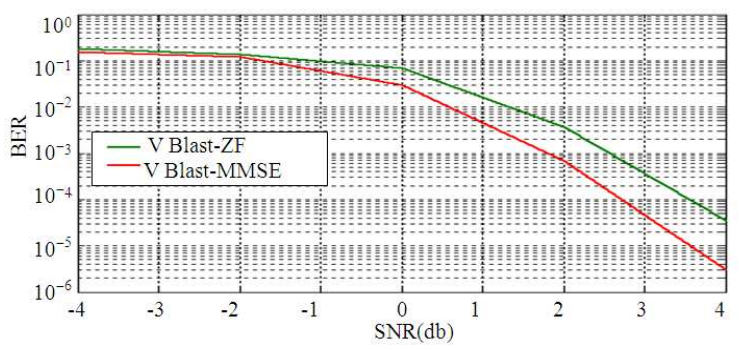

Fig. 6: Bit Error Rate (BER) performance of turbo coded MIMO-IDMA with ZF and MMSE for 50 users over rayleigh fading channel

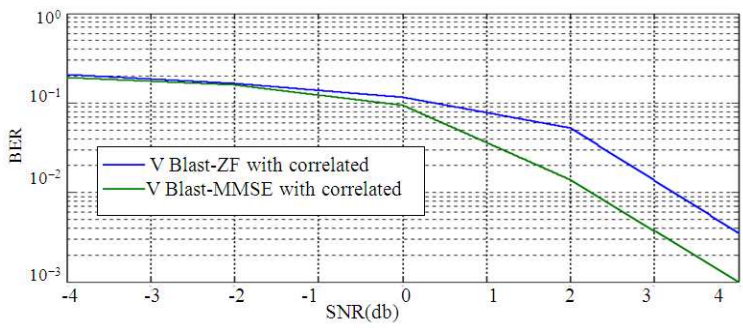

Fig.7: Bit Error Rate (BER) performance of turbo coded MIMO-IDMA ZF and MMSE for 50 users over correlated channel

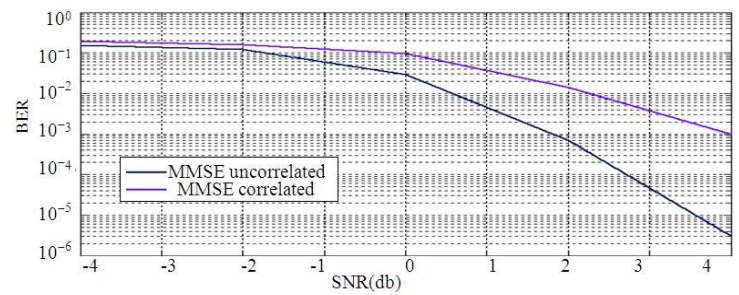

Fig. 8: Bit Error Rate (BER) performance of turbo coded MIMO-IDMA with MMSE over correlated and uncorrelated channel for 50 users 


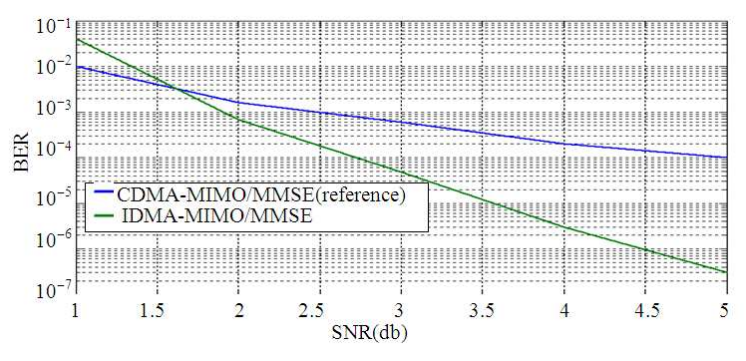

Fig. 9:Bit Error Rate (BER) performance of turbo coded MIMO-CDMA and MIMO-IDMA with MMSE detector over Rayleigh fading channel

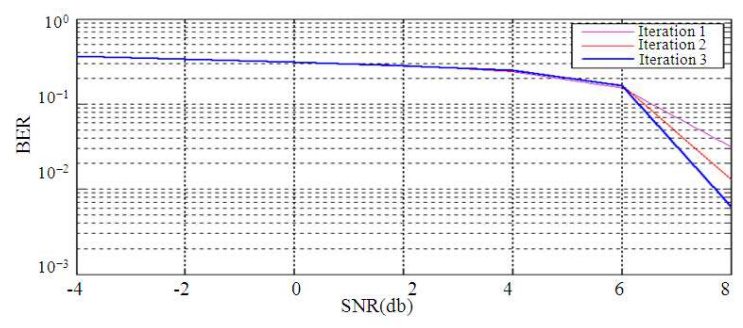

Fig. 10: Bit Error Rate (BER) performance of turbo coded MIMO-IDMA with ZF detector for SUI-1 channel model

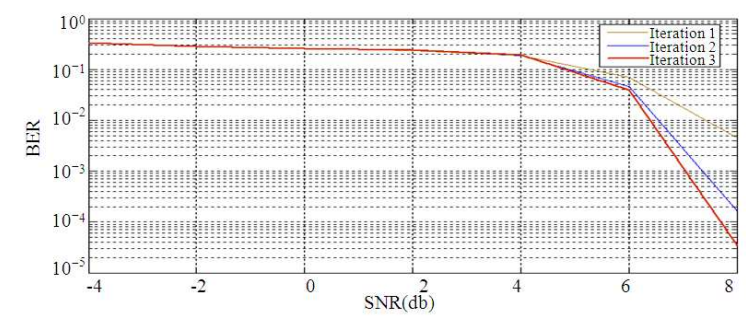

Fig. 11: Bit Error Rate (BER)performance of turbo coded MIMO-IDMA with ZF detector for SUI-3 channel model

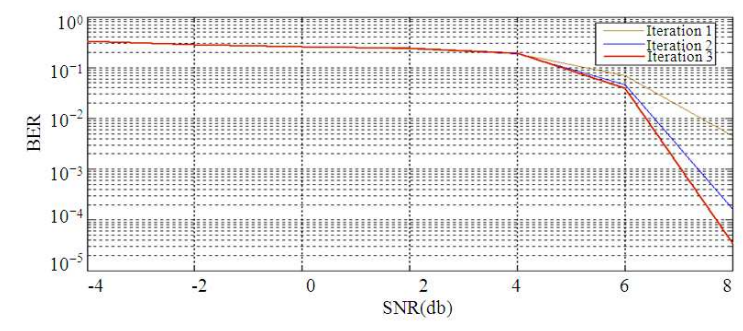

Fig. 12: Bit Error Rate (BER) performance of turbo coded MIMO-IDMA with ZF detector for SUI5 channel model

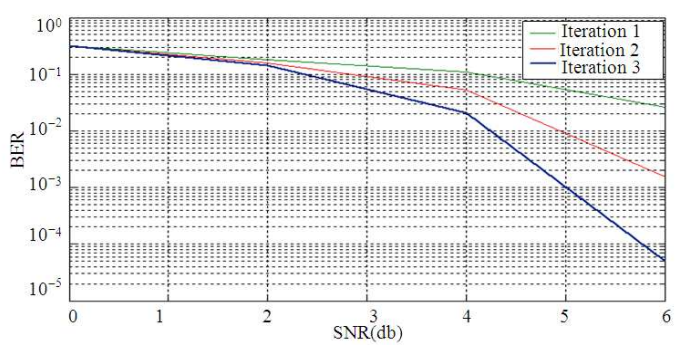

Fig. 13: Bit Error Rate (BER) performance of turbo coded MIMO-IDMA with MMSE detector for SUI-1 channel model

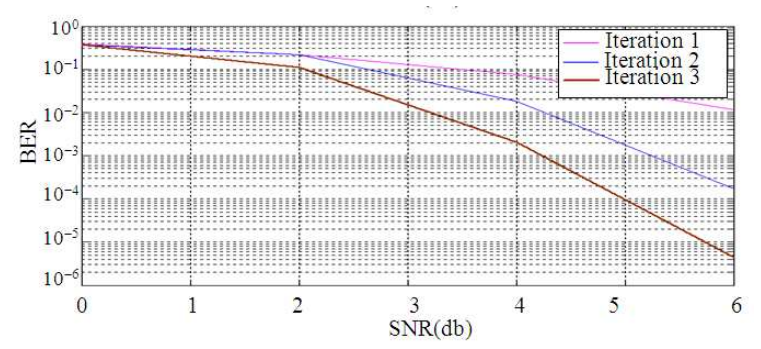

Fig.14:Bit Error Rate (BER) performance of turbo coded MIMO-IDMA MMSE for 50 users over SUI channel model-3

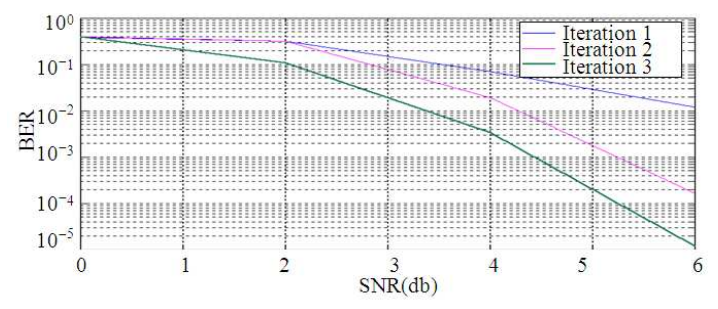

Fig. 15: Bit Error Rate (BER) performance of turbo coded MIMO-IDMA MMSE for 50 users over SUI channel model-5

The Fig. 13-15 shows the results for an MIMOIDMA System with MMSE detector for SUI 1,3,5 channel model. The Fig. 16-18 shows the omparison of MIMO-IDMA ZF MUD and MMSE MUD for SUI 1, 3, 5 channel model. From the analysis it has been observed that MIMO-IDMA outperform MIMO-CDMA System with MMSE MUD and with MMSE MUD, we can achieve superior performance interms of BER as compared to ZF MUD. 


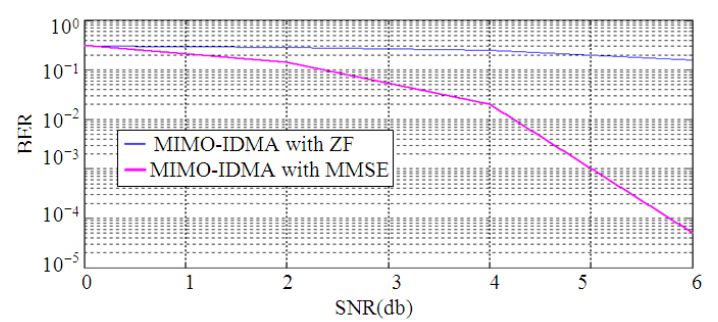

Fig.16: Comparison of Bit Error Rate (BER) performance of coded MIMO-IDMA with ZF and MMSE MUD for SUI model-1(50 users)

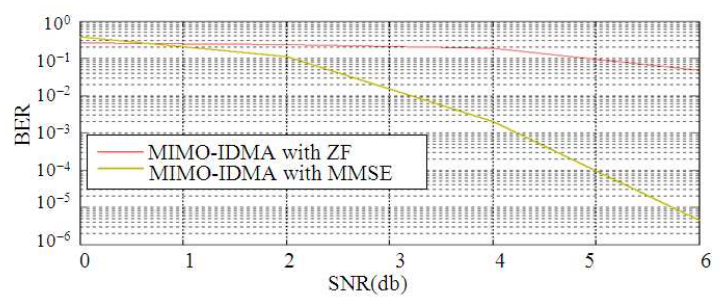

Fig.17:Comparison of Bit Error Rate (BER) performance of coded MIMO-IDMA with ZF and MMSE MUD for SUI channel model-3 (50 users

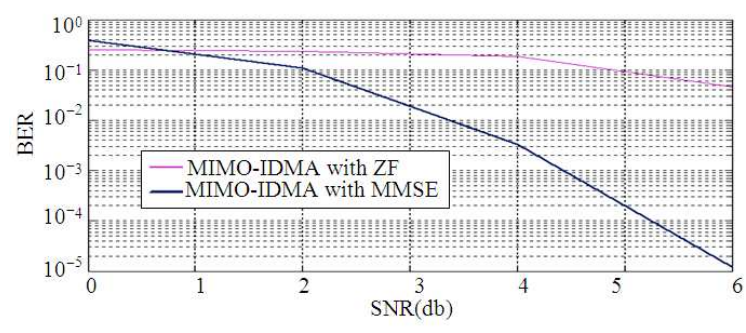

Fig. 18: Comparison of BER performance of coded MIMO- IDMA with ZF and MMSE MUD for SUI channel model-5(50 users)

\section{CONCLUSION}

In this article, we evaluated the performance of turbo assisted MIMO -IDMA system with sub-optimal MUD. It is discerned from the analysis that multipath can severely degrade the system performance. Also, MUI can result in further degradation in terms of achievable BER. It is shown through simulation that, in the context of multi-user scenario, MIMO-IDMA system with MUD can mitigate multi-user interference and inter antenna interference with less detection complexity. Further our analysis show that MIMOIDMA can support more number of users there by resulting in higher capacity. Furthermore, MIMOIDMA system aided by iterative decoding algorithm and MMSE MUD results in significant performance improvement compared to ZF MUD.

\section{REFERENCES}

Almutairi, A.F., H.A. Latchman, T.F. Wong, M. Lee and S.L. Miller, 2003. Performance of MMSE receiver based CDMA system with higher order modulation formats in a fading channel. Wireless Personal Commun., 25: 117-136. DOI: 10.1023/A:1023682119528

Brink, S.T., 2001. Convergence behavior of iteratively decoded parallel concatenated codes. IEEE Trans. Commun., 49: 1727-1737. DOI: $10.1109 / 26.957394$

Muthaiyah, S., 2004. Key Success Factors of 3rd Generation Mobile Network Services for MCommerce in Malaysia. Am. J. Applied Sci., 1: 261-265. DOI: 10.3844/ajassp.2004.261.265

Nagaradjane, P., A.S.S. Vasan and L. Krishnan, 2009a. A robust space time co-channel interference mitigation and detection technique for multiuser MIMO multicarrier DS/CDMA systems. Proceedings of the 1st International Conference, Wireless Vitae, Wireless Communication, Vehicular Technology, Information Theory and Aerospace \& Electronic Systems Technology, May, 18-20, IEEE Xplore Press, Aalborg, pp: 842846.

DOI:

10.1109/WIRELESSVITAE.2009.5172559

Nagaradjane, P., A.S.S. Vasan, L. Krishnan and A. Venkataswamy, 2009b. Joint VBLAST/STBC assisted MC DS/CDMA system with multiuser detection. Proceeding of the $5^{\text {th }}$ International Conference, WiCOM, Wireless Communications, Networking and Mobile Computing, Sep. 24-26, IEEE Xplore Press, Beijing, pp: 1-4. DOI: 10.1109/WICOM.2009.5301618

Novak, C., F. Hlawatch and G. Matz, 2007. MIMOIDMA: Uplink multiuser MIMO communications using interleave division Multiple access and lowcomplexity iterative receivers. Proceedings of the IEEE International Conference on ICASSP Acoustics, Speech and Signal, April, 15-20, IEEE Xplore Press, Honolulu, HI, III-225 - III-228. DOI: 10.1109/ICASSP.2007.366513 
Ping, L., L. Liu, K.Y. Wu and W.K. Leung, 2003. Interleave-Division Multiple-Access (IDMA) communications. City University of Hong Kong. http://74.125.155.132/scholar?q=cache:6xT6STbMaUJ:scholar.google.com/\&hl=en\&as_sdt=0, 5

Prabagarane, N., M. Ramakrishnan, T. Divya, M. Thomas, B. Jalaja. 2008. Performance evaluation of multi stage receivers for coded signals in MIMO Channels. Proceedings of the 4th International Conference on WiCOM, Wireless Communications, Networking and Mobile Computing, Oct. 12-14, IEEE Xplore Press, Dalian, pp: 1-4. DOI: 10.1109/WiCom.2008.123

Schoeneich, H. and P.A. Hoeher, 2004. Adaptive interleave-divisionmultiple access -A potential air interface for $4 \mathrm{G}$ Bearer Services and Wireless LANs. University of Kiel. http://74.125.155.132/scholar?q=cache:PAsA89ND KKoJ:scholar.google.com/+Schoeneich,+H.+and+ P.A.+Hoeher, $+2004 \& h l=e n \&$ as_sdt $=0,5$
Sreedhar, D. and A. Chockalingam, 2006. MMSE receiver for multi-user interference cancellation in uplink OFDMA. Proceeding of the IEEE, 63rd Vehicular Technology Conference, May, 7-10, IEEE Xplore Press, Melbourne, Vic., pp: 21252129. DOI: 10.1109/VETECS.2006.1683231

Sayadi, F., M. Ismail, N. Misran, K. Jumari and M. Abdullah, 2009. Efficient detection algorithm for a multiple-input and multiple-output multiuser multicarrier code division multiple access in timevarying channels. Am. J. Eng. Applied Sci., 2: 635642. DOI: 10.3844/AJEASSP.2009.635.642

Telatar, I.E., 1999. Capacity of multi-antenna Gaussian channels. Eur. Trans. Tel., 10: 585-595. DOI: 10.1002/ETT.4460100604

Verdu, S., 1998. Multi-user Detection. 1st Edn., Cambridge University Press, New York, ISBN: 0521593735, pp: 451. 